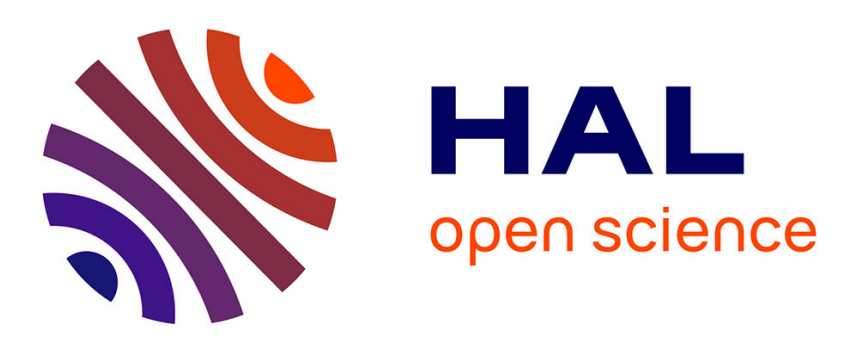

\title{
Possible evidence for a methane source in Enceladus' ocean
}

\author{
Alexis Bouquet, Olivier Mousis, J. Hunter Waite, Sylvain Picaud
}

\section{To cite this version:}

Alexis Bouquet, Olivier Mousis, J. Hunter Waite, Sylvain Picaud. Possible evidence for a methane source in Enceladus' ocean. Geophysical Research Letters, 2015, 42 (5), pp.1334-1339. 10.1002/2014GL063013 . hal-01434378

\section{HAL Id: hal-01434378 \\ https://hal.science/hal-01434378}

Submitted on 12 Nov 2021

HAL is a multi-disciplinary open access archive for the deposit and dissemination of scientific research documents, whether they are published or not. The documents may come from teaching and research institutions in France or abroad, or from public or private research centers.
L'archive ouverte pluridisciplinaire HAL, est destinée au dépôt et à la diffusion de documents scientifiques de niveau recherche, publiés ou non, émanant des établissements d'enseignement et de recherche français ou étrangers, des laboratoires publics ou privés. 


\section{Geophysical Research Letters}

\author{
RESEARCH LETTER \\ 10.1002/2014GL063013 \\ Key Points: \\ - Enceladus' ocean is modeled as a \\ subglacial lake \\ - The conditions in Enceladus' internal \\ ocean are met for production \\ of clathrates \\ - Efficient trapping of methane reduces \\ its abundance below plume levels
}

\section{Correspondence to:}

A. Bouquet,

alexis.bouquet@swri.org

\section{Citation:}

Bouquet, A., O. Mousis, J. H. Waite, and S. Picaud (2015), Possible evidence for a methane source in Enceladus' ocean, Geophys. Res. Lett., 42, 1334-1339, doi:10.1002/2014GL063013.

Received 31 DEC 2014 Accepted 29 JAN 2015 Accepted article online 2 FEB 2015 Published online 11 MAR 2015

\section{Possible evidence for a methane source in Enceladus' ocean}

\author{
Alexis Bouquet $^{1,2}$, Olivier Mousis ${ }^{3,4}$, J. Hunter Waite ${ }^{2}$, and Sylvain Picaud ${ }^{4}$ \\ ${ }^{1}$ Department of Physics and Astronomy, University of Texas at San Antonio, San Antonio, Texas, USA, ${ }^{2}$ Space Science and \\ Engineering Division, Southwest Research Institute, San Antonio, Texas, USA, ${ }^{3}$ LAM (Laboratoire d'Astrophysique de \\ Marseille) UMR 7326, Aix Marseille Université, CNRS, Marseille, France, ${ }^{4}$ Observatoire des Sciences de I'Univers de \\ Besançon, Université de Franche-Comté, Institut UTINAM, CNRS/INSU, UMR 6213, Observatoire des Sciences de I'Univers \\ de Besançon,Besançon, France,
}

Abstract The internal ocean of Enceladus can be expected to present conditions favorable to the trapping of volatiles in clathrates. This process could influence the eventual composition of the ocean and therefore of the plumes emitted by the south polar region. Here we used a statistical thermodynamic model to assess which species detected in the plumes by the Cassini-Ion and Neutral Mass Spectrometer experiment are trapped in clathrates. We treated Enceladus' internal ocean as a terrestrial subglacial lake with a mixture of dissolved volatiles indicated by plume gas measurements. We find that the conditions for clathrate formation are met in this ocean, except above $20 \mathrm{~km}$ or in hypothetical hot spots. The formation of multiple guest clathrates depletes methane below plume levels, suggesting that clathrates eventually dissociate (releasing methane) in the fissure that connects the ocean to the surface or that another mechanism (such as hydrothermal reactions) is compensating by adding methane into the ocean.

\section{Introduction}

Since the detection by the Cassini spacecraft of the gas emission of plumes by Saturn's moon Enceladus [Dougherty et al., 2006; Porco et al., 2006; Waite et al., 2006], the possibility of an internal ocean has been suggested, gaining more support as data were gathered and interpreted [Postberg et al., 2009, 2011; less et al., 2014]. In order to understand the processes in the interior of Enceladus, it is necessary to determine how representative the composition of the plumes is of the ocean. In this letter we investigate how the production of clathrate hydrates could impact an ocean with dissolved volatiles in the proportions detected in the plumes.

Enceladus' ocean is expected to feature a combination of conditions favorable to clathrate production: availability of large quantities of water, low temperature in the interior, high pressure, and presence of species with high propensity to being trapped in clathrate, such as methane [Sloan and Koh, 2008]. Furthermore, the trapping of species into multiple guest clathrates could alter their proportion in the ocean, since not all species would be equally depleted. Finally, trapping in clathrate is a likely process to explain possible noble gas deficiencies in planetary environments [Mousis et al., 2011, 2013a].

Section 2 gives an overview of the statistical thermodynamic model used in this study and the assumptions used as our starting point. It also discusses the selection of the species to be investigated and the conditions in the ocean. Section 3 presents the results of the calculations. Section 4 is devoted to discussion and conclusions.

\section{Ocean Model}

\subsection{Subglacial Lake Model}

In this study, we apply to Enceladus' internal ocean the approach used by Mousis et al. [2013b] to depict the time evolution of Lake Vostok's composition on Earth. It is based on a thermodynamic statistical model giving the abundances of species dissolved in the ocean, and the proportions of guests trapped in clathrate, produced at each time step. We refer the reader to the aforementioned paper for further information on the model itself.

We assume the existence of a process continuously bringing gases to the ocean; if Enceladus' ocean is considered in a steady state, the expulsion of volatiles with the plumes implies a gas input. We consider continual melting/freezing of the surrounding ice, releasing trapped volatiles or bubbles of gas, with 
Table 1. Cassini Measurements in Enceladus' Plumes ${ }^{a}$

\begin{tabular}{lcccc} 
Species & Mixing Ratio & \multicolumn{1}{c}{$\mathrm{X} / \mathrm{H}_{2} \mathrm{O}$} & $x_{K}^{\text {gas }}$ & \multicolumn{1}{c}{$x_{K}^{\text {comet }}$} \\
\hline $\mathrm{H}_{2} \mathrm{O}$ & 0.87 & 1 & 1 & \\
$\mathrm{H}_{2}$ & 0.11 & 0.126 & & \\
$\mathrm{CO}_{2}$ & $5.2 \times 10^{-3}$ & $5.98 \times 10^{-3}$ & 0.399 & 0.23 \\
$\mathrm{CH}_{4}$ & $1.9 \times 10^{-3}$ & $2.18 \times 10^{-3}$ & 0.133 & 0.06 \\
$\mathrm{NH}_{3}$ & $6.1 \times 10^{-3}$ & $7.01 \times 10^{-3}$ & & \\
$\mathrm{CO}$ & $\leq 6.4 \times 10^{-3}$ & $7.36 \times 10^{-3}$ & 0.233 & 0.46 \\
$\mathrm{~N}_{2}$ & $\leq 6.1 \times 10^{-3}$ & $7.01 \times 10^{-3}$ & 0.233 & 0.18 \\
$\mathrm{HCN}$ & $\leq 1.2 \times 10^{-3}$ & $1.38 \times 10^{-3}$ & & \\
$\mathrm{H}_{2} \mathrm{~S}$ & $2.1 \times 10^{-5}$ & $3.26 \times 10^{-5}$ & $2.17 \times 10^{-3}$ & 0.06 \\
$\mathrm{Ar}$ & $\mathrm{N} / \mathrm{A}$ & $\mathrm{N} / \mathrm{A}$ & $1.5 \times 10^{-2}$ & $1.5 \times 10^{-2}$ \\
$\mathrm{Kr}$ & $\mathrm{N} / \mathrm{A}$ & $\mathrm{N} / \mathrm{A}$ & $9.0 \times 10^{-6}$ & $9.0 \times 10^{-6}$ \\
$\mathrm{Xe}$ & $\mathrm{N} / \mathrm{A}$ & $\mathrm{N} / \mathrm{A}$ & $8.8 \times 10^{-7}$ & $8.8 \times 10^{-7}$ \\
\hline
\end{tabular}

${ }^{a}$ All data are from slow flybys E14, E17, and E18, except $\mathrm{H}_{2} \mathrm{~S}$ (flyby E7). Fourth column shows proportion in the mixture used in our model. Last column is the proportions for an alternative composition (comet-like). Species not likely to form clathrate have been excluded. convection in the crust ensuring availability of volatiles at the water/ice interface (conditions for convection are discussed in Behounkova et al. [2013] and can reasonably be assumed to be met at least at some periods of Enceladus' life); hydrothermal activity could also factor in. The exact process of addition does not affect the conclusion.

With time, the gas dissolved in the ocean reaches a partial pressure sufficient to trigger clathrate formation. Steady state is attained when the mole fractions of volatiles species withdrawn by clathrates from the ocean are similar to those delivered to the ocean.

Parameters used in the model are given in Mousis et al. [2013a] and Sloan and Koh [2008].

The time step of the model is the time needed to add a given quantity of gas per unit volume of the ocean; this quantity is arbitrary as we are interested in the steady state eventually reached.

The initial mixture of volatiles in the ocean is similar to the one continuously added. We refer section 2.2 for the choice of volatiles considered.

\subsection{Choice of Species}

Species to be incorporated in our calculations meet two criteria: (i) they are among the most abundant ones detected in the plume, and (ii) they can be entrapped in clathrates. Results of Cassini measurements in Enceladus' plumes for the most abundant species are listed in Table 1. Because there is an ambiguity in measurement between $\mathrm{N}_{2}$ and $\mathrm{CO}$ at mass 28 [Waite et al., 2009], we know the $\mathrm{N}_{2}+\mathrm{CO}$ abundance but not the actual proportion of those two species. $\mathrm{C}_{2} \mathrm{H}_{4}$ could also contribute to mass 28 , but the common interpretation is that $\mathrm{CO}$ and $\mathrm{N}_{2}$ are prevalent; moreover, there is no data on trapping of $\mathrm{C}_{2} \mathrm{H}_{4}$ in clathrates. Here we assumed an equal repartition between $\mathrm{CO}$ and $\mathrm{N}_{2}$ in our calculations. This puts $\mathrm{N}_{2}$ at $0.35 \%$ relative to $\mathrm{H}_{2} \mathrm{O}$, consistent with the measurements of Ultraviolet Imaging Spectrograph establishing an upper value at $0.5 \%$ [Hansen et al., 2011]. This results in a mixture composed of $\mathrm{CO}, \mathrm{CO}_{2}, \mathrm{CH}_{4}, \mathrm{~N}_{2}$, and $\mathrm{H}_{2} \mathrm{~S}$ as they have been reliably measured during the multiple flybys of Enceladus by Cassini. The mole fractions of the species included in the mixtures used in our model are given in Table 1. We have also added the heavy noble gases $\mathrm{Ar}, \mathrm{Kr}$, and $\mathrm{Xe}$ to the mixture in order to track their evolution. The chosen noble gas abundances relative to $\mathrm{H}_{2} \mathrm{O}$ correspond to $\mathrm{Ar} / \mathrm{O}, \mathrm{Kr} / \mathrm{O}$, and $\mathrm{Xe} / \mathrm{O}$ ratios derived from the solar abundances given in Mousis et al. [2008]. Argon and Krypton have not been firmly detected by Cassini-lon and Neutral Mass Spectrometer (INMS), which makes the examination of any possible cause of their depletion valuable. Xenon is out of the mass range of INMS, and any conclusion about its depletion would have to be confirmed by other, future means.

We first used a mixture of volatiles directly following the INMS measurements of the plumes (next to last column of Table 1). The proportion of species in the plume mixture does not allow us to infer the structure of clathrate (Structure I or Structure II) that could be formed in the ocean. While $\mathrm{CO}$ and $\mathrm{CO}_{2}$ are both known to form Structure I clathrate [Sloan and Koh, 2008], $\mathrm{N}_{2}$ is prone to form Structure II structures. Moreover, the ambiguity of measurements between $\mathrm{CO}$ and $\mathrm{N}_{2}$ means that the mixture could be as well dominated by Structure I-forming or Structure II-forming species. We, therefore, show and discuss results for both cases.

An alternative and more hypothetical volatile composition has also been considered, based on cometary volatiles from Hale-Bopp [Bockelée-Morvan et al., 2004]. The mole fraction derived from the nucleus production is given in the last column of Table 1. 


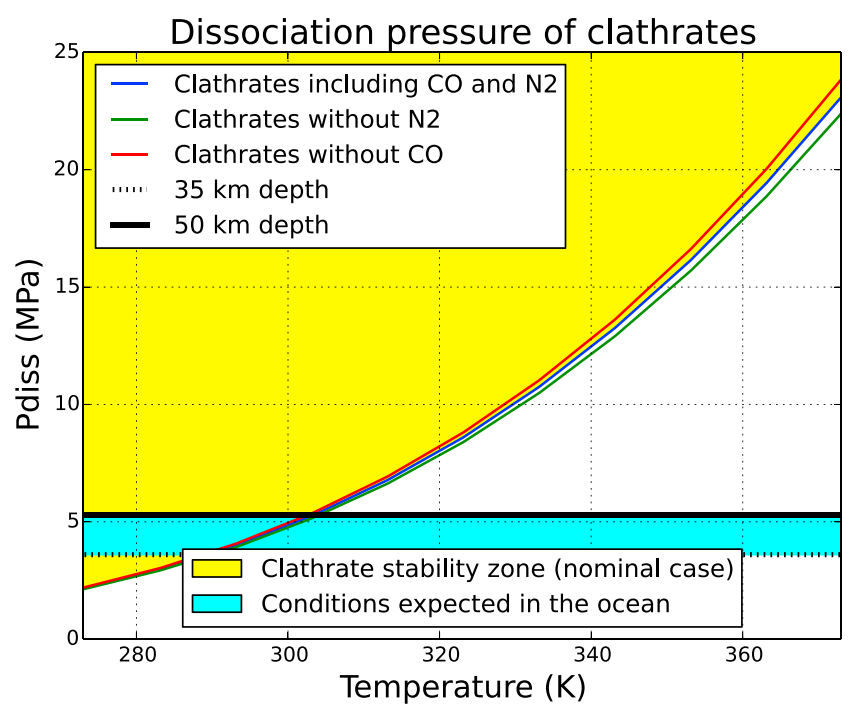

Figure 1. Effect of temperature and composition on the dissociation pressure of clathrates. The two horizontal dashed lines correspond to the column pressure integrated down to $35 \mathrm{~km}$ depth (bottom line) and $50 \mathrm{~km}$ depth (top line).

\subsection{Conditions of Pressure and Temperature}

Pressure and temperature in the ocean are critical factors for clathrate formation and storage. We, therefore, have assessed the dissociation pressure of clathrates featuring the guests determined in section 2.2 (for plume-like composition), depending on a plausible range of temperature, and compared the results to the expected conditions in the ocean. To account for the ambiguity between $\mathrm{CO}$ and $\mathrm{N}_{2}$ in the clathrate composition, the calculations have been performed for three cases: $\mathrm{CO}$ and $\mathrm{N}_{2}$ abundances being equal (nominal case), $\mathrm{CO}$ being absent in favor of $\mathrm{N}_{2}$, and $\mathrm{N}_{2}$ being absent in favor of $\mathrm{CO}$.

In Matson et al. [2012], a temperature of $273.15 \mathrm{~K}$ is assumed, which is the most plausible choice, especially near the

ice/ocean interface. Lower temperatures may be envisioned for a liquid ocean due to the presence of $\mathrm{NH}_{3}$, but without any firm constraint on its abundance the exact value would only be a guess. Similarly, it is very possible that some parts of the ocean are far hotter (at least up to $\sim 373 \mathrm{~K}$ ), but this could be limited to hot spots [Matson et al., 2007; Hsu et al., 2014]. Figure 1 displays the dissociation pressure of clathrates computed in the $273-373 \mathrm{~K}$ range against column pressures integrated down to several depths. It shows that (i) the variations in clathrate composition only have a small effect on the dissociation pressure and (ii) this effect is negligible at the lowest temperatures that are expected to dominate in the major part of the ocean. Figure 1 also shows that clathrate formation is plausible in the ocean. The vertical extension of the ocean has been constrained by gravimetric measurements, which suggest that the rock/ocean and ice/ocean interfaces are at $\sim 50 \mathrm{~km}(\sim 5.3 \mathrm{MPa})$ and 35-40 km (3.6-4.2 MPa) depths, respectively [less et al., 2014]. At $\sim 273 \mathrm{~K}$, clathrate formation requires a pressure of $\sim 2.2 \mathrm{MPa}$, corresponding roughly to a depth of $22 \mathrm{~km}$, well above the

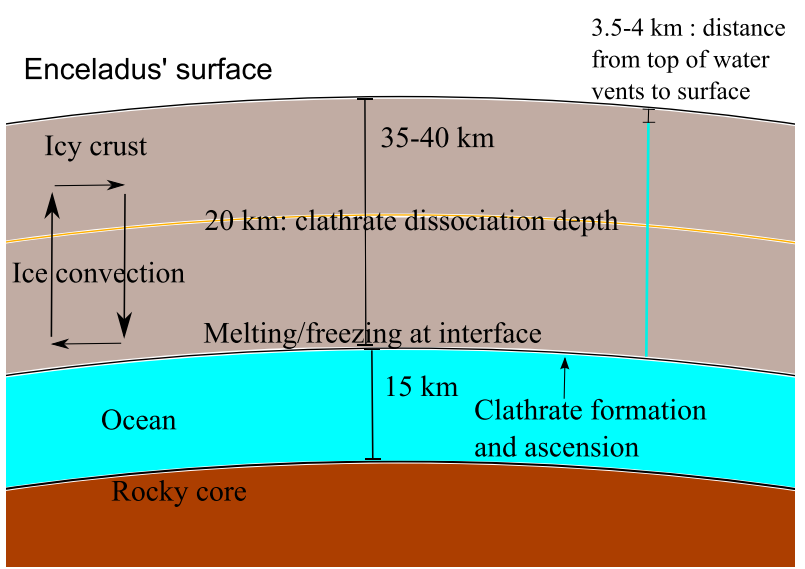

Figure 2. Layout of Enceladus' ocean and ice crust considered for this study. Yellow line shows the depth above which clathrates hosting plume species are not stable. Clathrate formation is susceptible to occur at any point of the ocean where pressure and temperature conditions are met. expected ice/ocean interface. On the other hand,temperatures above $300 \mathrm{~K}$ would prevent clathrate formation (and trigger their dissociation) as the dissociation pressure would exceed the pressure expected at the ocean's bottom. The layout considered for the study is summarized in Figure 2.

The conditions are therefore present in all the ocean for clathrate to form. Their subsequent fate, however, depends on a number of factors. Depending on their density, they may ascend to the ice/ocean interface or sink to the bottom of the ocean. In the former case, they would form a clathrate layer at the interface, in the latter, they could 

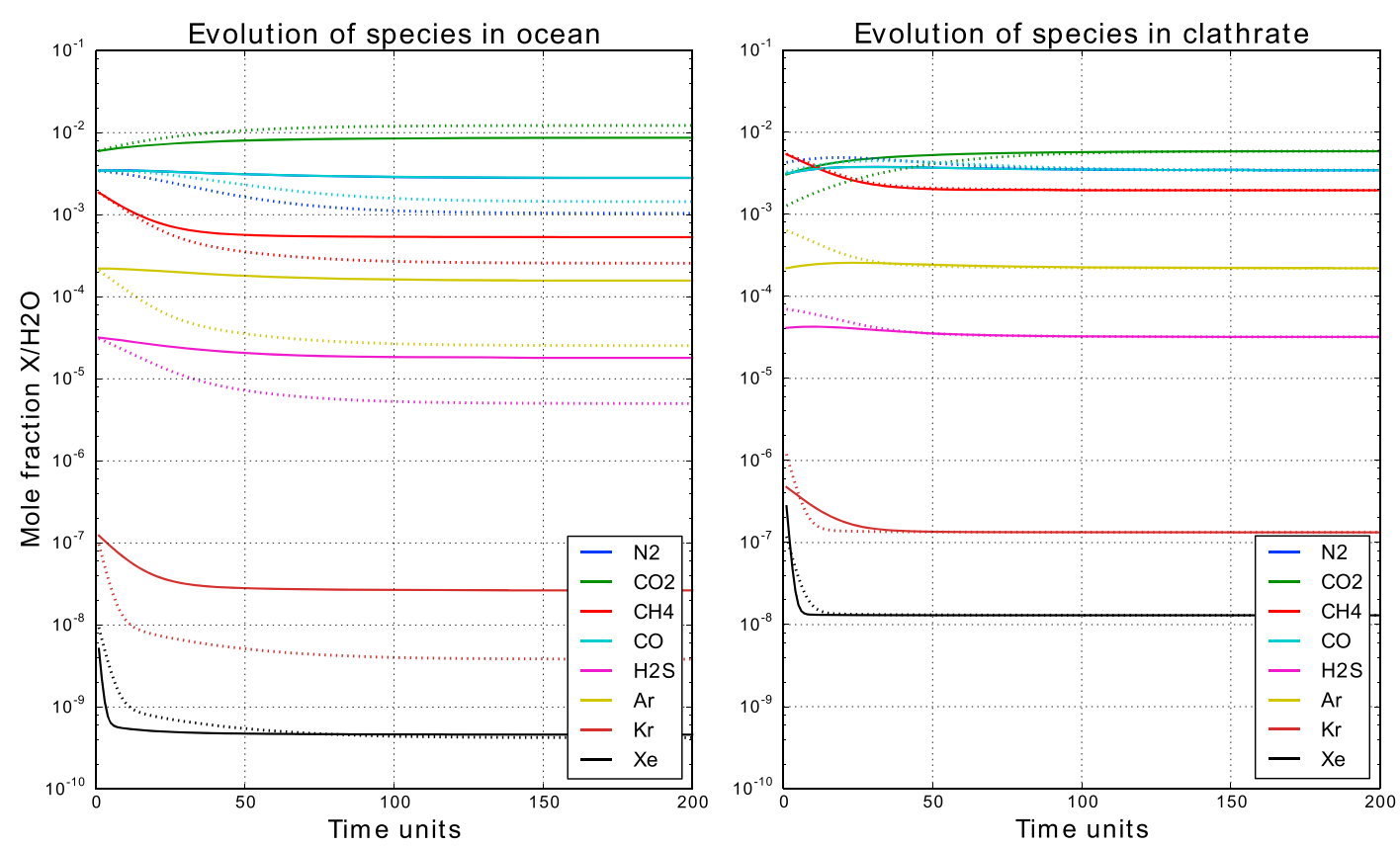

Figure 3. Considering a gas input based on plumes: Mole fractions of $\mathrm{N}_{2}, \mathrm{CO}_{2}, \mathrm{CH}_{4}, \mathrm{CO}, \mathrm{H}_{2} \mathrm{~S}, \mathrm{Ar}$, $\mathrm{Kr}$, and Xe dissolved in the (left) ocean and trapped into (right) clathrates and expressed as a function of time units. Solid and dashed lines represent formation cases of Structures I and II clathrates, respectively.

be dissociated by high temperatures caused by hydrothermal activity, the exact result depending on the distribution of heat (homogeneous or punctual "hot spots").

\section{Results}

We have computed the density of clathrates formed (assuming a volatile input based on plumes) following the approach of Sloan and Koh [2008], assuming that their cages are fully filled. These clathrates may exist in Structure I or II, namely the two most widespread clathrate structures in natural environments. We found densities of 1.04 and 0.97 for Structures I and II clathrates, respectively. We have then compared those values to the density of sea salt water at high pressure, which is close to 1.030 in the 3.6 to $5.3 \mathrm{MPa}$ range (35-50 km depth), a value calculated with the Computer Support Group (CSG) Water Density Calculator, based on the equation of Millero et al. [1980]. We then conclude that Structure II clathrates would ascend in the ocean, even if the cages are fully filled. On the other hand, the behavior of Structure I clathrates is more uncertain since their density is very close to the ocean's value. Given the large uncertainties concerning the ocean's composition and the fact that the density of Structure I clathrates could be lower if the cages were partly filled, we cannot derive any firm conclusion about their fate in the ocean. It is still possible that some Structure I clathrates may ascend in the ocean.

Figure 3 shows the evolution of the mole fractions of species dissolved in the ocean and trapped in clathrates as a function of time using a volatile mixture based on the plumes, measured by Cassini INMS. The calculations have been performed at $5 \mathrm{MPa}$ (close to $50 \mathrm{~km}$ depth). Additional calculations show negligible variations if they were performed at different pressures (e.g., $10 \mathrm{MPa}$ ). Among the various species, all compounds except $\mathrm{CO}_{2}$ undergo depletion in the ocean with time. Methane depletion is especially noticeable. Figure 4 shows the evolution when using a cometary volatiles mixture. Similarly, methane is depleted below plume levels. It is also interesting to note that $\mathrm{H}_{2} \mathrm{~S}$ stays at much higher levels than in the plume, implying a consumption process, such as sulfide formation at the water-rock interface.

Alternative input compositions have been tried to match the species final abundance with plumes composition: while this could be accomplished for other species, it proved to be impossible with methane. We can, therefore, conclude that clathrate formation efficiently depletes methane below measured plumes levels, implying that methane is not in equilibrium, due to a recent release or clathrate disruption. It also appears that, among noble gases, xenon is depleted by 1 order of magnitude in both Structures I and II. 

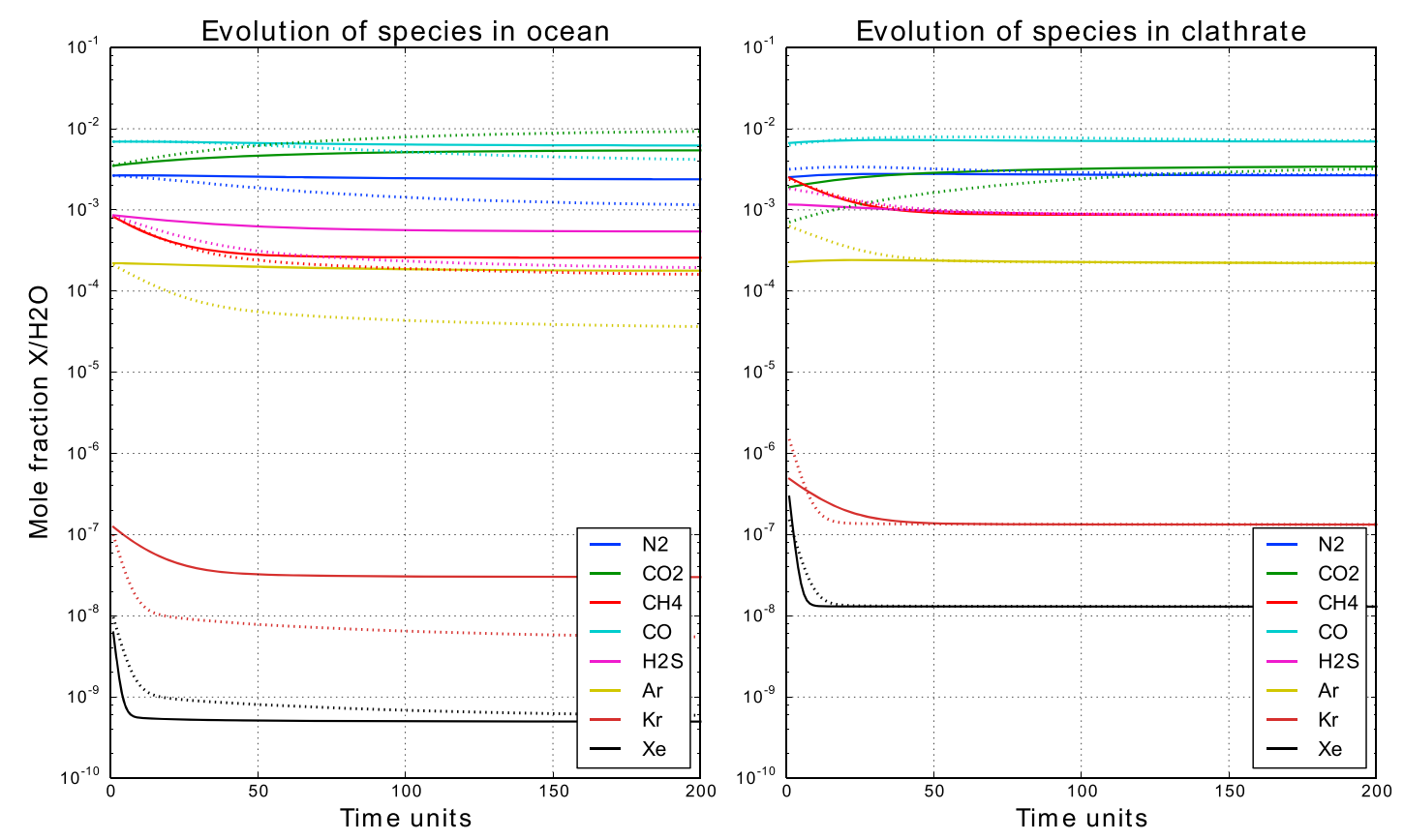

Figure 4. Considering a gas input based on comet Hale-Bopp: Mole fractions of $\mathrm{N}_{2}, \mathrm{CO}_{2}, \mathrm{CH}_{4}, \mathrm{CO}, \mathrm{H}_{2} \mathrm{~S}, \mathrm{Ar}$, $\mathrm{Kr}$, and Xe dissolved in the (left) ocean and trapped into (right) clathrates and expressed as a function of time units. Solid and dashed lines represent formation cases of Structures I and II clathrates, respectively.

Krypton undergoes a stronger depletion in the Structure II case than in the Structure I case, and argon is almost unaffected in the Structure I case and depleted by 1 order of magnitude if Structure II formation is assumed.

\section{Discussion and Conclusions}

The conditions for volatile clathration are present in Enceladus' ocean. We can, therefore, assume that multiple guest clathrates featuring some of the species detected in the plumes are formed. The most striking result is the efficient depletion of methane. The proportions between volatiles measured in the plumes are not possible in a saturated ocean, as methane would be strongly depleted due to its trapping in clathrate. To match the plume's composition, this implies subsequent dissociation of the clathrate (releasing methane) or that methane is supersaturated in the ocean due to fast addition (hydrothermal activity). After ascension to the top of the ocean, clathrates could form a layer at the ice/ocean interface. Hydrostatic considerations indicate that water in vents will raise up to $90 \%$ of the ice crust thickness (i.e., $3.5 \mathrm{~km}$ below the surface; other mechanisms are necessary to create plumes); depending on the kinetic of their dissociation, clathrates could reach this height and their eventual dissociation would increase pressure and participate in plumes creation and enrichment in volatiles.

The methane content of the plumes has not noticeably changed since their detection, implying that the related processes are steady over a several years time scale. If the time scales of trapping in clathrates and of transfer throughout the ocean are shorter, this would strongly point to a steady methane production at approximately the plumes' ejection rate. The experimental methane entrapping rates [Gainey and Elwood Madden, 2012], applied to the surface of the South Polar Region, suggest a yearly methane entrapping that is 40,000 times the amount of methane ejected in the plumes (assuming a plume rate of $350 \mathrm{~kg} / \mathrm{s}$ ) over the same time scale. Additionally, numerical simulations for Europa's internal ocean [Goodman and Lenferink, 2012] indicate that hydrothermal activity generates ascending currents at a speed of 1-5 cm/s, giving a transfer time scale well below a year. Dedicated simulations are required to ascertain how this can be transposed to Enceladus, as a faster rotation rate may impact upward currents [Aurnou et al., 2008].

Therefore, an explanation of the processes in Enceladus' ocean, which ultimately leads to the production of the plumes, must include the trapping of volatiles in clathrates as a factor, as it alters the composition of the ocean and can be involved in creating the conditions for the observed plumes. 


\section{Acknowledgments}

O. Mousis is supported by CNES. This work is also supported by the Cassini Project through JPL subcontract 1405853 and by the Rosina project through JPL subcontract 1296001. This work has been carried out, thanks to the support of the $A^{*}$ MIDEX project (ANR-11-IDEX-0001-02) funded by the "Investissements d'Avenir" French Government program, managed by the French National Research Agency (ANR). Thanks to Krista Soderlund for fruitful discussions. Results of simulations are available on demand to corresponding author.

The Editor thanks Sascha Kempf and an anonymous reviewer for their assistance in evaluating this paper.

\section{References}

Aurnou, J., M. Heimpel, L. Allen, E. King, and J. Wicht (2008), Convective heat transfer and the pattern of thermal emission on the gas giants, Geophys. J. Int., 173, 793-801, doi:10.1111/j.1365-246X.2008.03764.x.

Behounkova, M., G. Tobie, G. Choblet, and O. Čadek (2013), Impact of tidal heating on the onset of convection in Enceladus's ice shell, Icarus, 226, 898-904, doi:10.1016/j.icarus.2013.06.033.

Bockelée-Morvan, D., J. Crovisier, M. J. Mumma, and H. A. Weaver (2004), The composition of cometary volatiles, in Comets II, edited by M. C. Festou, H. U. Keller, and H. A. Weaver, pp. 391-423, Univ. of Ariz. Press, Tucson.

Dougherty, M. K., K. K. Khurana, F. M. Neubauer, C. T. Russell, J. Saur, J. S. Leisner, and M. E. Burton (2006), Identification of a dynamic atmosphere at Enceladus with the Cassini magnetometer, Science, 311, 1406-1409, doi:10.1126/science.1120985.

Gainey, S. R., and M. E. Elwood Madden (2012), Kinetics of methane clathrate formation and dissociation under Mars relevant conditions, Icarus, 218, 513-524, doi:10.1016/j.icarus.2011.12.019.

Goodman, J. C., and E. Lenferink (2012), Numerical simulations of marine hydrothermal plumes for Europa and other icy worlds, Icarus, 221, 970-983, doi:10.1016/j.icarus.2012.08.027.

Hansen, C. J., et al. (2011), The composition and structure of the Enceladus plume, Geophys. Res. Lett., 38, L11202, doi:10.1029/2011GL047415.

Hsu, H.-W., et al. (2014), Silica Nanoparticles provide evidence for hydrothermal activities at Enceladus, Nature, in press.

less, L., et al. (2014), The gravity field and interior structure of Enceladus, Science, 344, 78-80, doi:10.1126/science.1250551.

Matson, D. L., J. C. Castillo, J. Lunine, and T. V. Johnson (2007), Enceladus' plume: Compositional evidence for a hot interior, Icarus, 187, 569-573, doi:10.1016/j.icarus.2006.10.016.

Matson, D. L., J. C. Castillo-Rogez, A. G. Davies, and T. V. Johnson (2012), Enceladus: A hypothesis for bringing both heat and chemicals to the surface, Icarus, 221, 53-62, doi:10.1016/j.icarus.2012.05.031.

Millero, F. J., C.-T. Chen, A. Bradshaw, and K. Schleicher (1980), A new high pressure equation of state for seawater, Deep Sea Res., Part A, 27, 255-264, doi:10.1016/0198-0149(80)90016-3.

Mousis, O., Y. Alibert, D. Hestroffer, U. Marboeuf, C. Dumas, B. Carry, J. Horner, and F. Selsis (2008), Origin of volatiles in the main belt, MNRAS, 383, 1269-1280, doi:10.1111/j.1365-2966.2007.12653.x.

Mousis, O., J. I. Lunine, S. Picaud, D. Cordier, J. H. Waite Jr., and K. E. Mandt (2011), Removal of Titan's atmospheric noble gases by their sequestration in surface Clathrates, Astrophys. J. Lett., 740, L9, doi:10.1088/2041-8205/740/1/L9.

Mousis, O., J. I. Lunine, K. E. Mandt, E. Schindhelm, H. A. Weaver, S. Alan Stern, J. Hunter Waite, R. Gladstone, and A. Moudens (2013a), On the possible noble gas deficiency of Pluto's atmosphere, Icarus, 225, 856-861, doi:10.1016/j.icarus.2013.03.008.

Mousis, O., A. Lakhlifi, S. Picaud, M. Pasek, and E. Chassefière (2013b), On the abundances of noble and biologically relevant gases in lake Vostok, Antarctica, Astrobiology, 13, 380-390, doi:10.1089/ast.2012.0907.

Porco, C. C., et al. (2006), Cassini observes the active south pole of Enceladus, Science, 311, 1393-1401, doi:10.1126/science.1123013.

Postberg, F., S. Kempf, J. Schmidt, N. Brilliantov, A. Beinsen, B. Abel, U. Buck, and R. Srama (2009), Sodium salts in E-ring ice grains from an ocean below the surface of Enceladus, Nature, 459, 1098-1101, doi:10.1038/nature08046.

Postberg, F., J. Schmidt, J. Hillier, S. Kempf, and R. Srama (2011), A salt-water reservoir as the source of a compositionally stratified plume on Enceladus, Nature, 474, 620-622, doi:10.1038/nature10175.

Sloan, E. D., and C. A. Koh (2008), Clathrate Hydrates of Natural Gases, CRC Press, Taylor and Francis, Boca Raton, Fla.

Waite, J. H., Jr. et al. (2006), Cassini ion and neutral mass spectrometer: Enceladus plume composition and structure, Science, 311, 1419-1422, doi:10.1126/science.1121290.

Waite, J. H., Jr. et al. (2009), Liquid water on Enceladus from observations of ammonia and ${ }^{40} \mathrm{Ar}$ in the plume, Nature, 460, 487-490, doi:10.1038/nature08153. 